\title{
Comparing different models of the development of the English verb category ${ }^{1}$
}

JULIAN M. PINE, ELENA V. M. LIEVEN, and CAROLINE F. ROWLAND

\section{Abstract}

In this study data from the first six months of 12 children's multiword speech were used to test the validity of Valian's (1991) syntactic performance-limitation account and Tomasello's (1992) verb-island account of early multiword speech with particular reference to the development of the English verb category. The results provide evidence for appropriate use of verb morphology, auxiliary verb structures, pronoun case marking, and $S V O$ word order from quite early in development. However, they also demonstrate a great deal of lexical specificity in the children's use of these systems, evidenced by a lack of overlap in the verbs to which different morphological markers were applied, a lack of overlap in the verbs with which different auxiliary verbs were used, a disproportionate use of the first person singular nominative pronoun I, and a lack of overlap in the lexical items that served as the subjects and direct objects of transitive verbs. These findings raise problems for both a syntactic performance-limitation account and a strong verb-island account of the data and suggest the need to develop a more general lexicalist account of early multiword speech that explains why some words come to function as "islands" of organization in the child's grammar and others do not.

There has been a growing awareness in recent years of the shortcomings of models of grammatical development based on the gradual extension of cognitive-semantic categories. First, there is the problem that children's early grammatical knowledge does not appear to be restricted in the way that such models would seem to predict (Maratsos 1982, 1988; Maratsos and Chalkley 1980). For example, the set of nouns used by young children in Determiner + Noun sequences is semantically heterogeneous in the sense that it includes not only nouns denoting concrete objects (e.g. ball), but also nouns that denote actions (e.g. walk), nouns that denote locations (e.g. kitchen), and even nouns that denote abstractions (e.g. minute) (Valian 1986; Pine and Lieven 1997). 
Second, it can be shown that some of the broad cognitive-semantic categories to which such models typically appeal are not viable as the semantic core of categories in all of the world's languages. For example, use of the semantic category "agent" as a bootstrap to the syntactic category of "NP subject" would represent a false step in the acquisition of some ergative languages that carve up the semantics of agency in a rather different way from nominative-accusative languages (e.g. Bowerman 1985; Braine 1988a, 1992; Pye 1990).

Third, there is now a wealth of evidence that children are capable of acquiring linguistic distinctions that have little or no semantic base from very early in development. Thus, analyses of children's acquisition of the mass-count distinction in English (Gathercole 1985; Gordon 1985); noun/verb distinctions in Hebrew (Levy 1988); and linguistic gender in a variety of different languages (Karmiloff-Smith 1979; Levy 1983a, 1983b; Mills 1986; Perez-Pereira 1991) all suggest that children are sensitive to distributional properties of the language they are learning from a very early age.

These problems have tended to push the field in two directions: either toward nativist performance-limitation accounts of early multiword speech (e.g. Pinker 1984; Valian 1986, 1991) or toward lexical constructivist accounts (e.g. Tomasello 1992; Tomasello and Brooks i.p.). Thus, Valian (1986) argues that the semantic heterogeneity of the lexical items that participate in children's early structures suggests that the child is operating with syntactic categories from the beginning. On the other hand, Tomasello (1992), while acknowledging the evidence for semantic heterogeneity, argues that the lexical specificity of children's early production suggests that their knowledge is much more limited in scope, reflecting a process of functionally based distributional analysis organized around particular predicate structures or "verb islands."

The present study represents an attempt to use data from the first six months of 12 children's multiword speech to test the validity of these different models with respect to the development of the English verb category. The aim is, first, to investigate whether the data support the attribution of syntactic subject, auxiliary verb, and verb categories to young language-learning children and, second, to assess the extent to which the lexical specificity of young children's early production is consistent with a verb-island account.

\section{Syntactic performance-limitation accounts of the development of the verb category}

The demise of "semantics-first" models of grammatical development has coincided with a reemergence of nativist performance-limitation accounts 
of children's early multiword speech (e.g. Pinker 1984; Valian 1986, 1991). According to Valian (1986), the semantic heterogeneity of children's early production, together with the very low frequency of grammatical errors in the data, suggest that the child is operating with syntactic categories such as determiner, noun, and noun phrase from the beginning. She goes on to argue (Valian 1991) for the early attribution of syntactic subject and auxiliary verb categories, and hence for an adultlike syntactic account of the data read through severe performance limitations. This is on the basis, first, that, even before $M L U=2.0$, American children appear to understand that English requires subjects (in the sense that they include subjects in their speech at least twice as often as Italianspeaking children); second, that nominatively case-marked pronouns are relatively common in children's early production, but nominative casemarking errors relatively rare; and, third, that limited though correct use of modal auxiliaries is in evidence from very early in development.

Valian's (1991) analysis is intended, at least in part, as a critique of Guilfoyle and Noonan's (1992) maturational model of language acquisition, which draws a strong distinction between lexical and functional stages in the child's early development and, hence, predicts subject optionality and an absence of correctly case-marked pronouns and modal auxiliaries in children's early multiword speech. Valian's data are quite compelling in this context. However, the extent to which they support the validity of a syntactic performance-limitation account of the data is much more questionable. This is because Valian's decision to analyze at the level of the syntactic categories hypothesized rather than at the level of the lexical items actually used by the child means that she effectively ignores the possibility that the data can be explained in more limitedscope terms (Pine and Martindale 1996). Moreover, this is particularly problematic in the context of attributing categories such as subject, auxiliary verb, and, by implication, verb because there is already plenty of evidence for lexical specificity in children's early use of these categories. This includes evidence for specificity in the use of verb morphology, with different morphological markers initially being applied to different populations of verbs (Bloom et al. 1980; Clark 1996); evidence for specificity in the use of auxiliary verb structures, with knowledge about particular lexical auxiliaries failing to generalize from one sentence structure to another (Kuczaj and Maratsos 1983); and evidence for specificity in the use of pronoun case marking, which suggests that it may be possible to explain high rates of correct nominative case marking in terms of knowledge about the privileges of occurrence of particular lexical items, typically the first-person singular nominative form $I$ (Lieven et al. 1997; Rispoli 1994). 
When taken together these findings raise doubts about the validity of attributing syntactic categories such as subject, auxiliary verb, and verb simply on the basis of limited though correct use of instances of these categories and suggest the need for a stronger test that takes into account evidence of lexical specificity in children's early production. One of the aims of the present study is therefore to provide such a test by looking for positive evidence of these categories in the form of overlap in the verbs that occur with different morphological markers and auxiliary verbs; contrastive use of case-marked pronouns; and overlap in the nouns that occur as the subjects and direct objects of transitive verbs. The assumption is that in order to attribute knowledge of a particular category to the child, one needs to show not only that the child can use instances of the category correctly, but also that this knowledge generalizes from one instance of the category to another. Different lexical instances of a category (e.g. the auxiliary) should thus show overlap in their privileges of occurrence in the child's speech (e.g. in the verbs with which they cooccur).

\section{Lexical-constructivist accounts of the development of the verb category}

Probably the strongest constructivist alternative to a syntactic performance-limitation account is Tomasello's (1992) verb-island hypothesis. According to this view, children start producing multiword speech without any knowledge either of syntactic-role categories such as "subject" and "direct object" or of semantic-role categories such as "agent" and "patient," but gradually build verb-specific categories such as "hitter" and "thing hit" on the basis of their experience with particular predicates. Children's early verbs and relational terms are thus seen as individual islands of organization in an otherwise unorganized grammatical system, and children's learning of word-order rules and morphological marking is assumed to proceed on a verb-by-verb basis, with verb-general marking awaiting the formation of a paradigmatic verb category. Indeed, Tomasello argues on the basis of evidence both from naturalistic multiword speech data and from experimental studies that there is a development asynchrony in the acquisition of the noun and verb categories in English. Thus, whereas even very young children show great facility in slotting nonce nouns into familiar verb structure (Tomasello and Olguin 1993), their knowledge about SVO word order seems to be lexically specific in that they not only fail to generalize it from one verb to another (Olguin and Tomasello 1993), but are also unable to use it as a cue for sentence comprehension, at least in the absence of additional supporting 
cues such as animacy and/or pronoun case marking (Akhtar and Tomasello 1997).

The verb-island hypothesis represents a radical departure from previous constructivist models of early grammatical development and has a number of strengths. One of the most important of these is its emphasis on lexically based distributional learning and its consequent ability to account for the semantic heterogeneity of the words that participate in children's early structures. However, it also has two important weaknesses. The first of these is the fact that there is no independent motivation within Tomasello's model for the centrality of verbs or "verb islands" other than the intuitively plausible assumption that verbs are more central to the meaning of children's utterances than nouns because the events to which they refer define situations for young children, whereas the objects to which nouns refer participate in many different events. This would seem to imply that verb-island phenomena reflect a correlation between the noun-verb distinction at the linguistic level and some kind of argument-predicate distinction at the cognitive-semantic level. However, as Maratsos (1990) points out, this correlation is far from perfect even in children's early grammars, suggesting that the verb-island model's implicit reliance on such a relation may be something of a problem.

The second weakness is the fact that although the verb-island hypothesis provides a good fit to the data on children's lexically specific use of SVO structure, there are aspects of children's early production, as Akhtar and Tomasello themselves point out, that do not fit a strict verb-island account, including children's ability to deal with progressive verb morphology on a verb-general basis and children's acquisition of structures based around high-frequency items other than verbs (e.g. case-marked pronouns). This suggests that the lexical specificity of children's early production is not always "verb specificity" as such and implies the need to provide some kind of account of why some lexical items come to function as "islands" in the child's grammar and others do not. A further aim of the present study is therefore to assess the extent to which the lexical specificity of young children's early production is consistent with the verb-island hypothesis as a first step toward developing such an account.

Of course, it might be argued that, once one accepts the possibility that a relatively high proportion of children's early production may reflect rote learning on the part of the child (Peters 1983; Pine and Lieven, 1993), naturalistic data become indeterminate with respect to the question of the generalizations on which children's production is actually based. In principle this is true, and it should be borne in mind when interpreting the results that follow. However, we would argue that it is reasonable to 
assume that a child who produces a criterial number of different instances of a particular pattern has some knowledge of that pattern, provided that (i) the pattern is defined in terms of a particular lexical item (e.g. can't $+\mathrm{X}$ ) rather than an abstract category (e.g. auxiliary verb $+\mathrm{X}$ ); and (ii) the criterial number is set reasonably high. The only viable alternative to this strategy would be to demand experimental demonstrations of the psychological reality of each pattern using nonce words. However, while such experiments are clearly to be welcomed since they can provide very strong evidence for a particular piece of knowledge on the part of the child, it is worth pointing out that they are not themselves without problems since their inherent conservatism means that failures to demonstrate knowledge in such experiments may not always be easy to interpret.

To summarize, the present study represents an attempt to use data from the first six months of 12 children's multiword speech to test the validity of Valian's (1991) and Tomasello's (1992) accounts of early multiword speech with particular reference to the development of the English verb category. The central aim is to use the data on these children's early use of verb morphology, auxiliary verb structures, pronoun case marking, and SVO word order to answer the following questions:

1. Is children's early use of these systems productive and, if so, to what extent does it generalize across different verbs and hence support the attribution of syntactic subject, auxiliary verb, and verb categories (as opposed to knowledge of lexical structures based around particular instances of these categories)?

2. To what extent does children's early use of these systems provide evidence for lexical structures based around words other than verbs, particularly lexical structures in which verbs participate as arguments, and hence to what extent does it count against a strong version of the verb-island hypothesis?

\section{Method}

\section{Subjects}

Participants in the study were 12 children of mixed socioeconomic status whose parents had responded to an advertisement placed in the local newspaper. This included seven girls and five boys and three first-borns and nine later-borns. All of the children were from monolingual Englishspeaking families, and all were cared for primarily by their mothers, whose educational levels ranged from having left school at the age of 16 
to having completed a university degree. These children represent a subgroup of a larger sample of 26 children who were audio-recorded at 10,50 , and 100 words as part of a study of their early vocabulary development (Pine et al. 1996, 1997).

\section{Procedure}

Children were recruited to the present study on the basis that they had maternal-report vocabularies of approximately 100 words on an Anglicized version of the vocabulary checklist section of the MacArthur Communicative Development Inventory (Infants) and were hence in the early stages of multiword speech (see Pine et al. 1996 for a more detailed discussion of the actual checklist used). The children were then audiorecorded at home for a further six-month period, at monthly intervals for the first three months and at fortnightly intervals for the next three months, yielding a total of $10 \times 40$-minute audio-recordings per child (though, as can be seen from Table 1 below, some data points are missing for some of the children). The children ranged in age from $1 ; 3.7$ to $2 ; 0.18$ at the beginning of the study $(M=19.8$ months, $S D=3.0)$; and from $1 ; 10.5$ to $2 ; 7.4$ at the end of the study $(M=26.0$ months, $S D=2.9)$. The children's maternal-report vocabularies ranged in size from 95 to 129 words at the beginning of the study $(M=113.2, S D=10.6)$, and their MLUs from 1.06 to 1.72 at the beginning of the study $(M=1.26$, $S D=0.18)$ and from 1.59 to 3.08 at the end of the study $(M=2.21$,

Table 1. Subject details

\begin{tabular}{lclrlll}
\hline Subjects & Age range & $\begin{array}{l}\text { MLU } \\
\text { range }\end{array}$ & $\begin{array}{l}\text { No. of } \\
\text { tapes }\end{array}$ & $\begin{array}{l}\text { Total } \\
\text { utterance } \\
\text { tokens }\end{array}$ & $\begin{array}{l}\text { Multiword } \\
\text { utterance } \\
\text { tokens }\end{array}$ & $\begin{array}{l}\text { Multiword } \\
\text { utterance } \\
\text { types }\end{array}$ \\
\hline Rita & $1 ; 5.9-1 ; 10.28$ & $1.25-3.08$ & 10 & 2009 & 878 & 583 \\
Joey & $1 ; 4.2-1 ; 10.14$ & $1.06-2.73$ & 10 & 2188 & 895 & 770 \\
Julie & $1 ; 8.8-2 ; 2.28$ & $1.19-2.64$ & 10 & 945 & 484 & 414 \\
Jean & $2 ; 0.14-2 ; 7.4$ & $1.33-2.60$ & 9 & 1842 & 823 & 688 \\
Ricky & $1 ; 8.21-2 ; 3.4$ & $1.29-2.43$ & 7 & 1553 & 796 & 597 \\
Eva & $1 ; 6.27-2 ; 2.0$ & $1.22-2.36$ & 10 & 2081 & 755 & 594 \\
Helen & $1 ; 6.1-2 ; 0.1$ & $1.39-2.21$ & 9 & 1267 & 457 & 311 \\
Carl & $1 ; 7.15-2 ; 0.29$ & $1.10-2.01$ & 10 & 1350 & 349 & 260 \\
John & $1 ; 10.9-2 ; 3.9$ & $1.09-2.00$ & 8 & 2359 & 870 & 492 \\
Simon & $1 ; 7.21-2 ; 3.0$ & $1.24-1.79$ & 10 & 1819 & 489 & 282 \\
Olga & $1 ; 3.7-1 ; 10.5$ & $1.04-1.63$ & 10 & 1406 & 250 & 161 \\
Laura & $2 ; 0.18-2 ; 6.14$ & $1.06-1.62$ & 9 & 1788 & 513 & 364 \\
\hline
\end{tabular}


$S D=0.44)$. However, there was no significant correlation between age and vocabulary size at the beginning of the study $(r=0.07, d f=10$, n.s.), nor between age and MLU at the beginning of the study $(r=-0.11$, $d f=10$, n.s.) or age and MLU at the end of the study $(r=-0.09$, $d f=10$, n.s.).

\section{Recording session}

The 40-minute audio-recoding was based on two 20-minute recording sessions, the first of which was a recording of the child at lunch, and the second a recording of the child at play. In order to reduce the artificiality of the situation, no restrictions were placed on the presence of siblings or other family members during the recording sessions, and the investigator behaved as a participant observer throughout. However, an attempt was made to "leave the floor" to the child and his or her normal interactive partners as much as possible.

\section{Children's speech corpora}

The audio-recordings were orthographically transcribed into a computerized database using the CHAT system from the CHILDES project (MacWhinney 1995; MacWhinney and Snow 1985, 1990). The transcripts were then checked against the tapes by a second transcriber and used to build up a corpus of utterances for each child. The criteria for inclusion of utterances in these corpora were that the utterances were (a) fully intelligible; (b) complete (i.e. were not interrupted utterances or false starts); (c) used spontaneously by the child (i.e. were neither imitations nor self-repetitions); and (d) were neither strings of numbers nor fragments of songs or nursery rhymes. These corpora were searched for instances of regular verb morphology (i.e. progressive -ing, regular past tense -ed, and regular third person singular $-s$ ), auxiliary verb structures, case-marked pronouns, and utterances that included a verb together with a subject argument, a direct-object argument, or both. The data obtained in this way were then used in the analyses that follow.

\section{Results}

\section{Children's utterance corpora}

Table 1 presents data on the size of the children's utterance corpora together with the number of audio-recordings on which they were based, 
the number of multiword utterance types and tokens that were included, and the children's age and MLU ranges. These data are ordered in terms of the children's highest recorded MLU, and it can be seen that despite the fact that all the data were drawn from the first six months of these children's multiword speech, there is considerable variation in the MLU ranges included, with some children still in Brown's stage I at the end of the study, others in stages II and III, and one child in stage IV, though only at the final recording session (Brown 1973).

\section{Verb morphology}

Data on the number of verb types and verb tokens marked with the progressive, regular past tense, and regular third person singular morphemes are presented in Table 2. It can be seen from these data that the majority of the children produced quite a large number of progressive types and tokens and at least some tokens of the regular past tense and the regular third person singular. However, the number of different past tense and third person singular types was typically very small, suggesting that for most of the children use of these morphemes was limited to a handful of unanalyzed forms.

The question of the productivity of the children's verb morphology was addressed by calculating the proportion of verb types marked with a particular morpheme that also occurred in the unmarked (i.e. bare

Table 2. Type and token frequencies for use of verb morphology

\begin{tabular}{llrrrrr}
\hline Subjects & $\begin{array}{l}\text { Tokens } \\
\text {-ing }\end{array}$ & -s & -ed & $\begin{array}{l}\text { Types } \\
\text {-ing }\end{array}$ & -s & -ed \\
\hline Rita & 62 & 9 & 8 & 17 & 2 & 4 \\
Joey & 69 & 12 & 17 & 32 & 5 & 8 \\
Julie & 32 & 4 & 7 & 12 & 2 & 3 \\
Jean & 58 & 3 & 4 & 30 & 2 & 4 \\
Ricky & 33 & 5 & 1 & 8 & 2 & 1 \\
Eva & 26 & 14 & 4 & 11 & 8 & 2 \\
Helen & 8 & 13 & - & 4 & 2 & - \\
Carl & 32 & - & - & 11 & - & - \\
John & 1 & 1 & 1 & 1 & 1 & 1 \\
Simon & 32 & - & 16 & 22 & - & 2 \\
Olga & 22 & - & - & 7 & - & - \\
Laura & 18 & - & 2 & 4 & - & 1 \\
Mean & 32.8 & 5.1 & 5.0 & 13.3 & 2.0 & 2.2 \\
\hline
\end{tabular}


stem) form (i.e. overlap = no. of verb types occurring both with and without the relevant inflection/no. of verb types occurring with the relevant inflection). These scores were then tested for overlap that was significantly different from zero using Fisher's Exact. Overlap scores for the three morphemes are presented in Table 3 together with scores for the percentage of verb types marked with either of each pair of morphemes that also occurred with both of the morphemes in the pair (i.e. overlap $=$ no. of verb types occurring with both inflection 1 and inflection $2 /$ no. of verb types occurring with either inflection 1 or inflection 2). The data show that eight of the 12 children, including two stage I children (Simon and Olga), met the productivity criterion for the progressive morpheme (i.e. had overlap scores that were significantly different from zero). However, only two of the more advanced children met the productivity criterion for the regular past tense and regular third person singular morphemes (Joey and Eva, and Joey and Jean, respectively). Moreover, there was very little overlap in the verbs with which different morphological markers were used and hence very little evidence of category-general marking. Of course, for most of the children this was hardly surprising because only the progressive morpheme appeared to be productive in their speech at this stage. However, there was also very little overlap for the three children who did pass the productivity criterion for two or more morphemes. Thus, Joey had overlap scores of $1 / 39$ for the progressive and past tense, $2 / 35$ for the progressive and third person

Table 3. Overlap scores for the verb types with which different morphemes occurred

\begin{tabular}{|c|c|c|c|c|c|c|}
\hline \multirow[t]{2}{*}{ Subjects } & \multicolumn{3}{|c|}{$\begin{array}{l}\text { Proportion of marked verbs } \\
\text { that also occurred in } \\
\text { unmarked form }\end{array}$} & \multicolumn{3}{|c|}{$\begin{array}{l}\text { Proportion of verbs } \\
\text { occurring in either form that } \\
\text { also occurred in both forms }\end{array}$} \\
\hline & -ing & $-s$ & -ed & -ing/-s & -ing/-ed & s/-ed \\
\hline Rita & $10 / 17^{a}$ & $2 / 2$ & $2 / 4$ & $2 / 17$ & $0 / 21$ & $0 / 6$ \\
\hline Joey & $22 / 32^{a}$ & $5 / 5^{a}$ & $4 / 8^{a}$ & $2 / 35$ & $1 / 39$ & $0 / 13$ \\
\hline Julie & $7 / 12^{a}$ & $1 / 2$ & $0 / 3$ & $1 / 13$ & $0 / 15$ & $0 / 5$ \\
\hline Jean & $21 / 30^{a}$ & $2 / 2$ & $4 / 4^{a}$ & $1 / 31$ & $0 / 34$ & $0 / 6$ \\
\hline Ricky & $3 / 8$ & $2 / 2$ & $1 / 1$ & $0 / 10$ & $0 / 9$ & $0 / 3$ \\
\hline Eva & $6 / 11^{a}$ & $7 / 8^{\mathrm{a}}$ & $2 / 2$ & $2 / 17$ & $0 / 13$ & $0 / 10$ \\
\hline Helen & $2 / 4$ & $2 / 2$ & - & $0 / 6$ & - & - \\
\hline Carl & $5 / 11^{a}$ & - & - & - & - & - \\
\hline John & $0 / 1$ & $1 / 1$ & $0 / 1$ & $0 / 2$ & $0 / 2$ & $0 / 2$ \\
\hline Simon & $14 / 22^{a}$ & - & $0 / 2$ & - & $0 / 24$ & - \\
\hline Olga & $5 / 7^{a}$ & - & - & - & - & - \\
\hline Laura & $3 / 4$ & - & $1 / 1$ & - & $0 / 5$ & - \\
\hline
\end{tabular}

a. Indicates an overlap score significantly different from zero at $p<0.05$. 
singular, and $0 / 13$ for the past tense and third person singular, none of which was significantly different from zero; while Jean had an overlap score of $0 / 34$ for the progressive and past tense and Eva an overlap score of $2 / 17$ for the progressive and third person singular, neither of which was significantly different from zero.

These findings do not count directly against a syntactic performancelimitation account of children's early multiword speech. However, they do fail to provide any positive evidence for verb-general marking and are hence at least consistent with the view that children are constructing distributionally defined subclasses of verbs on the basis of their participation in different morphological frames. This conclusion is consistent with a lexicalist account of early grammatical development. However, it is not consistent with a strong version of the verb-island hypothesis, because it implies that children are generalizing across subcategories of verbs from very early in development. These subcategories may have a semantic flavor to them (Bloom et al. 1980; Clark 1996). However, it is worth pointing out that this "semantic flavor" may be essentially epiphenomenal. That is to say, it may reflect the interaction between a semantically blind distributional analyzer and semantic-distributional patterning in the input, rather than the workings of a learning mechanism that is itself tuned to particular aspects of verb semantics (see Elman 1990 for a demonstration of how such pseudosemantic effects can occur).

\section{Auxiliary verb structures}

Data on the number of auxiliary verb tokens and number of different auxiliary + verb combinations in each child's corpus are presented in Table 4 together with a list of all of the different auxiliaries used by each child. Auxiliary $d o$ and main verb do were distinguished on distributional grounds. Thus instances of do were only classified as auxiliaries if they were followed by a main verb or a negative particle, or occurred in an utterance without a main verb or a direct object and appeared to substitute for a verb phrase in the previous discourse. Different auxiliary + verb combinations were defined as different pairs of auxiliaries and main verbs ignoring differences in polarity, tense, and word order.

It can be seen from these data that all of the children produced at least some auxiliary verb tokens in their early multiword speech and that several produced quite a large number of different auxiliary + verb combinations, supporting Valian's (1991) claim that limited though correct use of auxiliaries is in evidence from the beginning. However, it is, of course, impossible to tell from these data how lexically specific the children's 
Table 4. Frequency of auxiliary verb tokens and different auxiliary + verb combinations

\begin{tabular}{llcl}
\hline Subjects & Auxiliary types & $\begin{array}{l}\text { Auxiliary } \\
\text { tokens }\end{array}$ & $\begin{array}{l}\text { Auxiliary + verb } \\
\text { combinations }\end{array}$ \\
\hline Rita & can, do, be, have, shall, will & 51 & 19 \\
Joey & can, do, be, have, shall, will & 61 & 27 \\
Julie & can, do, be, have, could, should, will & 44 & 20 \\
Jean & can, do, be, have, might, should, will & 139 & 44 \\
Ricky & can, do, be, have & 55 & 16 \\
Eva & can, do, be, have & 62 & 22 \\
Helen & can, do, be, have & 31 & 10 \\
Carl & can, do, be, have, will & 43 & 10 \\
John & can, do, have & 7 & 6 \\
Simon & can, do, be, have, will & 56 & 16 \\
Olga & can, do, be, have, will & 11 & 5 \\
Laura & do, be, have, shall & 9 & 6 \\
Mean & & 47.4 & 16.8 \\
\hline
\end{tabular}

early auxiliary use was. This question was therefore investigated further by looking for overlap in the verbs with which different auxiliaries occurred. The auxiliaries used in this analysis were can, do, be, and have since these were by far the most frequent auxiliaries in the data, together accounting for an average of $90.3 \%$ of all of the children's different auxiliary + verb combinations. Overlap scores were calculated as follows: overlap $=$ no. of verb types occurring with both auxiliary 1 and auxiliary $2 /$ no. of verb types occurring with either auxiliary 1 or auxiliary 2 .

The results of this analysis are presented in Table 5, from which it can be seen that none of the children showed overlap that was significantly different from zero on any of the overlap measures (though Jean's overlap score for $d o$ and $b e$ was marginally significant at $p=0.054$ ). These results provide very little support for the attribution of syntactic auxiliary verb and verb categories to these children. On the other hand, given the number of different auxiliary + verb combinations produced, it seems likely that several of the children did have at least some productive lexical knowledge about the privileges of occurrence of particular lexical auxiliaries. This issue was therefore examined further by searching each of the children's corpora for evidence of lexical patterns of the form "lexical auxiliary +X." These were then evaluated using Braine's (1976) statistical criterion for the attribution of a productive positional pattern based on the binomial theorem (i.e. six different instances in the same order and no instances in a different order, or eight instances in the same order and one instance in a different order, etc.). This criterion is inevitably some- 
Table 5. Overlap scores for the verb types with which different auxiliaries occurred

\begin{tabular}{lllllll}
\hline Subjects & can/do & can/be & can/have & do/be & do/have & be/have \\
\hline Rita & $2 / 10$ & $1 / 10$ & $1 / 10$ & $1 / 4$ & $1 / 4$ & $1 / 3$ \\
Joey & $0 / 10$ & $0 / 15$ & $1 / 5$ & $0 / 17$ & $0 / 8$ & $0 / 13$ \\
Julie & $0 / 8$ & $0 / 9$ & $1 / 9$ & $0 / 7$ & $0 / 8$ & $2 / 7$ \\
Jean & $2 / 20$ & $3 / 19$ & $0 / 14$ & $4 / 22^{\mathrm{a}}$ & $1 / 17$ & $2 / 16$ \\
Ricky & $1 / 9$ & $0 / 7$ & $1 / 6$ & $0 / 9$ & $1 / 8$ & $0 / 6$ \\
Eva & $1 / 11$ & $1 / 9$ & $0 / 6$ & $2 / 14$ & $0 / 12$ & $1 / 9$ \\
Helen & $0 / 4$ & $1 / 3$ & $0 / 4$ & $0 / 6$ & $1 / 5$ & $0 / 6$ \\
Carl & $0 / 3$ & $0 / 7$ & $0 / 3$ & $1 / 5$ & $1 / 1$ & $1 / 5$ \\
John & $0 / 3$ & $0 / 2$ & $0 / 5$ & $0 / 1$ & $0 / 4$ & $0 / 3$ \\
Simon & $0 / 7$ & $1 / 7$ & $2 / 5$ & $0 / 7$ & $0 / 6$ & $1 / 6$ \\
Olga & $0 / 2$ & $0 / 2$ & $0 / 2$ & $0 / 2$ & $0 / 2$ & $0 / 2$ \\
Laura & $0 / 1$ & $0 / 3$ & $0 / 1$ & $0 / 4$ & $0 / 2$ & $1 / 3$ \\
\hline
\end{tabular}

a. Indicates an overlap score significantly different from zero at $p<0.10$.

what arbitrary. However, it is also relatively stringent in that it controls for chance by demanding that there should be statistically significantly more instances in which the relevant items occur in one order than in another.

Four of the most advanced children were found to have one productive positional pattern that met this criterion. Moreover, in each case the slot immediately following the auxiliary was always filled by a verb. Thus, Rita had six instances of a "can't $+X$ " pattern (e.g. "can't find it"); Joey had seven instances of a " $X_{1}$-'s $+X_{2}$ " pattern (e.g. "Little Bo Beep's crying"); and Jean and Eva both had nine instances of a "don't $+X$ " patterns (e.g. "don't eat pen"). These data suggest that children's use of auxiliary + verb combinations can be accounted for in terms of a mixture of rote-learned and lexically specific knowledge and would thus seem to count against a syntactic performance-limitation account. On the other hand, they are also inconsistent with a strong version of the verb-island hypothesis since they provide further evidence that some children are generalizing across subcategories of verbs from quite early in development.

\section{Pronoun case marking}

Table 6 presents data on the number of nominative case-marked pronoun targets in the children's corpora (excluding you and it, which have homonymous nominative and accusative forms). Also presented are data 
Table 6. Frequency of nominative case-marking contexts together with percentage error rates and the percentage of nominative contexts that were first person singular contexts

\begin{tabular}{lccc}
\hline Subjects & $\begin{array}{l}\text { Number of } \\
\text { nominative } \\
\text { contexts }\end{array}$ & Error rate (\%) & $\begin{array}{l}\text { First person } \\
\text { singular } \\
\text { contexts (\%) }\end{array}$ \\
\hline Rita & 19 & 0.0 & 52.6 \\
Joey & 145 & 1.4 & 92.4 \\
Julie & 71 & 23.9 & 77.5 \\
Jean & 216 & 8.8 & 76.9 \\
Ricky & 47 & 0.0 & 100.0 \\
Eva & 121 & 13.2 & 81.0 \\
Helen & 61 & 0.0 & 91.8 \\
Carl & 67 & 4.5 & 82.1 \\
John & 13 & 15.4 & 84.6 \\
Simon & 35 & 2.9 & 82.9 \\
Olga & 20 & 10.0 & 90.0 \\
Laura & 23 & 52.2 & 100.0 \\
Mean & 69.8 & 11.0 & 84.3 \\
\hline
\end{tabular}

on each child's nominative error rate and the proportion of his or her nominative targets that were instances of the first person singular. These data are broadly consistent with those of Valian (1991) in that the majority of the children's error rates are relatively low (though Laura and Julie are obvious exceptions to this pattern). However, they are also consistent with a lexically specific account of children's early case marking since they show that an average of $84.3 \%$ of children's nominative pronouns are first-person singular pronouns, suggesting that the vast majority of the children's correct case-marking performance can be accounted for in terms of knowledge of the privileges of occurrence of the single lexical item $I$.

This implies that largely correct use of nominatively case-marked pronouns does not represent sufficient grounds for attributing productive case-marking knowledge to children and that a more stringent test is needed requiring evidence of contrastive use. This issue was therefore investigated further by looking for evidence that the children discriminated between nominative and accusative contexts in their use of the accusative pronoun $m e$. This was done by calculating the percentage of each child's use of $m e$ that was correct and comparing this with chance. These percentages are presented in Table 7, from which it can be seen that none of the children showed performance that was significantly different from chance. This was largely because most of the children rarely used $m e$ in either nominative or accusative contexts. However, 
Table 7. Frequency of first person singular accusative pronouns and percentage of correct use

\begin{tabular}{lcc}
\hline Subjects & Tokens & Correct use (\%) \\
\hline Rita & 1 & 100.0 \\
Joey & 2 & 50.0 \\
Julie & 22 & 40.9 \\
Jean & 20 & 60.0 \\
Ricky & 1 & 100.0 \\
Eva & 4 & 0.0 \\
Helen & 1 & 100.0 \\
Carl & 1 & 0.0 \\
John & 1 & 0.0 \\
Simon & 1 & 0.0 \\
Olga & 1 & 100.0 \\
Laura & 1 & 100.0 \\
Mean & 4.7 & 54.2 \\
\hline
\end{tabular}

there were two children (Julie and Jean) who did use me relatively often, and their data also failed to provide any evidence of contrastive use.

These data would seem to provide very little support for the idea that these children have productive knowledge of nominative case marking and hence count against a syntactic performance-limitation account of the kind proposed by Valian (1991). However, they also suggest that children do have at least some productive lexical knowledge about the privileges of occurrence of the first person nominative pronoun $I$. This issue was therefore investigated further by searching each of the children's corpora for evidence of a productive positional pattern of the form "I + X" using Braine's (1976) criterion.

It was found that all of the children in the sample had an "I+X" pattern that met this criterion, except for Rita and Simon, who both had five correctly ordered instances and no incorrectly ordered instances and hence just failed to reach criterion. These findings thus count against a strong version of the verb-island hypothesis since they suggest that, although children's knowledge of pronoun case marking may be lexically specific, they also have at least some lexically specific knowledge of SVO word order that generalizes across different verbs.

\section{Subject-verb-object word order}

Table 8 presents data on the number of multiword utterance tokens that included a main verb together with a subject argument, a direct object 
argument, or both. Also presented are the percentage of these utterances that included a subject argument and the percentage that included a direct object argument, with the former category further subdivided into subjects of transitive verbs, subjects of intransitive verbs, and subjects of copulas. It should be noted that all of these figures exclude utterances involving double verb structures (e.g. "I want see Postman Pat"); utterances that did not conform to English SVO word order (e.g. "Wipe that John," where "John" was clearly intended as the "wiper" argument); and utterances containing errors involving double object marking (e.g. "Don't like it train").

It can be seen from these data that subject arguments occurred quite frequently in all of the children's speech - more frequently than direct object arguments for eight of the 12 children. This could be taken as support for Valian's (1991) claim that by $\mathrm{MLU}=2.0$ English-speaking children already know that English verbs require subjects. However, it can also be seen that quite a large percentage of these subjects $(44.7 \%$ on average) occurred with a single verb - the copula. This raises the possibility that a substantial proportion of these children's subject use could be explained in terms of a relatively small amount of lexically specific knowledge.

Of course, it is impossible to tell from the data presented in Table 8 precisely how lexically specific children's use of subjects was. This issue was therefore investigated further by calculating the percentage of each child's different subject + verb communication that could be accounted for by one of the five most common lexical patterns of the form "lexical subject $+X$ " or " $X+$ lexical verb." The results of this analysis are presented in Table 9, from which it can be seen that the five most common lexical patterns in each child's data together accounted for between $67.0 \%$ and $90.0 \%$ of all their different subject + verb combinations $($ Mean $=$ $75.1 \%$ ). This suggests that a substantial proportion of children's early subject use can be explained in terms of the acquisition of particular lexically specific formulae and raises doubts about the generality of children's knowledge of SVO word order.

The question of whether the children showed contrastive use of SVO word order was investigated by examining the number of different noun and pronoun types that occurred as the subjects and objects of transitive verbs and calculating overlap scores based on the proportion of transitive subject and object argument types that occurred as both the subject and object arguments of transitive verbs. The results of this analysis are presented in Table 10, from which it can be seen that for all of the children the number of different transitive subject types was much smaller than the number of different transitive object types. 
Table 8. Frequency of utterance tokens that included a verb and a subject and/or direct argument, and the percentage of these utterances that included a subject or direct object

\begin{tabular}{lllllll}
\hline Subjects & $\begin{array}{l}\text { Utterances } \\
\text { including a } \\
\text { verb and a } \\
\text { subject } \\
\text { and/or direct } \\
\text { object }\end{array}$ & $\begin{array}{l}\text { Utterances } \\
\text { including a } \\
\text { subject (\%) }\end{array}$ & $\begin{array}{l}\text { Utterances } \\
\text { including a } \\
\text { direct } \\
\text { object (\%) }\end{array}$ & $\begin{array}{l}\text { Subjects of } \\
\text { transitive } \\
\text { verbs (\%) }\end{array}$ & $\begin{array}{l}\text { Subjects of } \\
\text { intransitive } \\
\text { verbs (\%) }\end{array}$ & $\begin{array}{l}\text { Subjects } \\
\text { of copula } \\
\text { verbs (\%) }\end{array}$ \\
& & & & & \\
\hline Rita & 399 & 49.4 & 72.7 & 47.2 & 33.0 & 19.8 \\
Joey & 346 & 67.6 & 64.2 & 58.5 & 19.2 & 22.2 \\
Julie & 280 & 76.8 & 40.4 & 23.3 & 24.7 & 52.1 \\
Jean & 478 & 76.4 & 51.7 & 45.2 & 17.8 & 37.0 \\
Ricky & 349 & 79.9 & 52.7 & 45.9 & 22.6 & 31.5 \\
Eva & 387 & 76.0 & 51.9 & 42.2 & 10.9 & 46.9 \\
Helen & 275 & 76.0 & 45.5 & 29.2 & 10.0 & 60.8 \\
Carl & 191 & 73.8 & 50.3 & 35.1 & 19.9 & 45.5 \\
John & 210 & 59.5 & 51.9 & 21.6 & 8.0 & 70.4 \\
Simon & 284 & 50.0 & 59.5 & 28.2 & 13.3 & 58.5 \\
Olga & 101 & 52.5 & 59.4 & 35.8 & 11.3 & 52.8 \\
Laura & 188 & 49.5 & 60.6 & 33.3 & 28.0 & 38.7 \\
Mean & 290.7 & 65.6 & 55.1 & 37.1 & 18.2 & 44.7 \\
\hline
\end{tabular}

Table 9. The first five most common lexical patterns involving subjects and the percentage of each child's different subject + verb combinations for which they can account

\begin{tabular}{|c|c|c|c|}
\hline Subjects & $\begin{array}{l}\text { Subject-verb } \\
\text { combinations }\end{array}$ & $\begin{array}{l}\text { Accounted } \\
\text { for }(\%)\end{array}$ & Five most common lexical patterns \\
\hline Rita & 82 & 69.5 & $X+$ go, Mummy $+X, X+$ is, $X+$ do, $X+$ fall \\
\hline Joey & 105 & 69.5 & $I+X, X+$ is, $X+$ go, Mummy $+X, I t+X$ \\
\hline Julie & 81 & 74.1 & $\mathrm{X}+$ is, $\mathrm{I}+\mathrm{X}, \mathrm{X}+$ go, $\mathrm{Me}+\mathrm{X}, \mathrm{X}+$ get \\
\hline Jean & 123 & 69.9 & $\mathrm{I}+\mathrm{X}, \mathrm{X}+$ is, $\mathrm{He}+\mathrm{X}, \mathrm{X}+\mathrm{go}, \mathrm{X}+\mathrm{get}$ \\
\hline Ricky & 129 & 76.0 & $\mathrm{X}+$ go, $\mathbf{X}+$ is, Ricky $+\mathbf{X}, \mathbf{X}+$ do, $\mathbf{I}+\mathbf{X}$ \\
\hline Eva & 91 & 67.0 & $\mathrm{I}+\mathrm{X}, \mathrm{X}+$ is, $\mathrm{You}+\mathrm{X}, \mathrm{X}+\mathrm{go}, \mathrm{He}+\mathrm{X}$ \\
\hline Helen & 46 & 87.0 & $\mathrm{X}+$ is, Kelly $+\mathrm{X}, \mathrm{I}+\mathrm{X}, \mathrm{X}+$ go, Baby $+\mathrm{X}$ \\
\hline Carl & 41 & 87.8 & $\mathrm{I}+\mathrm{X}, \mathrm{X}+$ is, $\mathrm{He}+\mathrm{X}, \mathrm{X}+$ go, $\mathrm{X}+$ eat \\
\hline John & 38 & 78.9 & $\mathrm{X}+$ is, $\mathrm{I}+\mathrm{X}$, John $+\mathrm{X}, \mathrm{X}+$ get, $\mathrm{X}+$ go \\
\hline Simon & 54 & 66.7 & $X+$ is, $X+$ get, $X+$ go, $I+X, I t+X$ \\
\hline Olga & 20 & 90.0 & $I+X, X+$ is, $X+$ go, Mummy $+X$, Baby $+X$ \\
\hline Laura & 46 & 71.7 & $X+$ come,$X+$ go, $I+X, X+$ is, $M y+X$ \\
\hline Mean & 71.3 & 75.7 & \\
\hline
\end{tabular}


Table 10. Frequency of different transitive subject and direct object types and overlap measures for the proportion of these items that occurred as both subject and direct object arguments

\begin{tabular}{llll}
\hline Subjects & $\begin{array}{l}\text { Transitive subject } \\
\text { types }\end{array}$ & $\begin{array}{l}\text { Direct object } \\
\text { types }\end{array}$ & Overlap \\
\hline Rita & 16 & 55 & $5 / 66^{\mathrm{a}}$ \\
Joey & 14 & 77 & $7 / 84^{\mathrm{a}}$ \\
Julie & 13 & 45 & $1 / 57$ \\
Jean & 16 & 80 & $7 / 89^{\mathrm{a}}$ \\
Ricky & 15 & 56 & $1 / 70$ \\
Eva & 16 & 70 & $3 / 83$ \\
Helen & 6 & 51 & $2 / 55$ \\
Carl & 6 & 29 & $0 / 35$ \\
John & 11 & 40 & $4 / 47$ \\
Simon & 10 & 47 & $2 / 55$ \\
Olga & 4 & 24 & $0 / 28$ \\
Laura & 8 & 38 & $1 / 45$ \\
\hline
\end{tabular}

a. Indicates an overlap score significantly different from zero at $p<0.05$.

Moreover, only three of the most advanced children in the sample showed overlap in subject and object use that was significantly different from zero. This suggests that the nouns and pronouns initially used by children as the subject and object arguments of transitive verbs tend to come from different populations and hence that there is no real positive evidence in most of these children's corpora for the contrastive use of SVO word order.

This conclusion obviously counts against a syntactic performancelimitation account of the data. However, given that it rests on evidence that children restrict the use of particular nouns and pronouns to particular positions in transitive verb structures, it is not really consistent with a verb-island account either. This is because it suggests that children are using lexically specific knowledge not only about the privileges of occurrence of verbs, but also about the privileges of occurrence of particular nouns and pronouns to structure their utterances. Indeed, one of the reasons why the number of different transitive subject types was typically so low in these children's data was that a large proportion of subject contexts were filled by the first person singular pronoun $I$, which, as we have already seen, occurred frequently within a highly productive "I $+X$ " pattern for most children. 


\section{Discussion}

The main aim of the present study was to use data from the first six months of 12 children's multiword speech to test the validity of Valian's (1991) and Tomasello's (1992) accounts of early multiword speech with particular reference to the development of the English verb category. The results provide evidence for appropriate use of verb morphology, auxiliary verb structures, pronoun case marking, and SVO word order from quite early in development. However, they also demonstrate a great deal of lexical specificity in the children's use of these systems, evidenced by a lack of overlap in the verbs to which different morphological markers were applied, a lack of overlap in the verbs with which different auxiliary verbs were used, a disproportionate use of the first person singular nominative pronoun $I$, and a lack of overlap in the lexical items that served as the subjects and direct objects of transitive verbs.

These findings count against a syntactic performance-limitation account of children's early multiword speech in two ways. First, they suggest that the "positive evidence" adduced in favor of such accounts hides lexical specificity in children's early language that tends to point toward a more limited-scope account (Pine and Martindale 1996). The implication is that the discovery of such "positive evidence" reflects the decision to analyze at the level of the syntactic categories hypothesized rather than at the level of the lexical items of which they are composed. This approach effectively assumes the knowledge for which evidence is being sought and ignores the possibility that a more limited-scope account might provide a better fit to the data.

Second, they raise doubts about the validity of arguments for syntactic categories based on low error rates (Rubino and Pine 1998). This is because it is impossible to interpret the significance of low error rates in the absence of any means of estimating the expected error rate - and, in practice, the expected error rate depends not only on theoretical considerations, but also on the pattern of lexical specificity found in the data themselves. Thus, as has been demonstrated both here and elsewhere (Lieven et al. 1997), low error rates with respect to nominative case marking are as much a reflection of the relative frequency with which different case-marked pronouns occur in young children's speech as they are of children's underlying knowledge and are hence, at best, rather difficult to interpret. Indeed, the children in the present study were just as likely to use the less frequently occurring first person singular accusative form in nominative position as they were to use it in accusative position, suggesting that their underlying knowledge of even the firstperson singular part of the system was actually quite limited and could 
be explained in terms of a fairly small amount of lexically specific knowledge.

Of course, it might be argued that these patterns of lexical specificity do not count directly against a performance-limitation account since it may be possible to explain them in other ways: for example, in terms of some kind of interaction between children's knowledge and the processing limitations under which they are operating; or in terms of an interaction between sampling considerations and semantic-pragmatic factors that tends to give children's early multiword speech a more lexically specific look than it might otherwise have. In principle, this is true. However, they do, at the very least, suggest the need for proponents of such models to develop empirical means of distinguishing them from constructivist models rather than simply explaining them away on an ad hoc basis once the data are in.

If, on the other hand, these data are taken at face value, it is clear that they are problematic not only for a performance-limitation account, but also for a strong version of the verb-island hypothesis. This is because they suggest that much of children's early knowledge is not organized around lexically specific verb structures, but around other high-frequency markers such as bound morphemes, auxiliary verbs, and case-marked pronouns. In one sense, these findings are not particularly new or surprising. After all, it has been known for many years that progressive -ing is one of the first morphemes to be acquired by children (Brown 1973), and Akhtar and Tomasello (1997) have themselves recently demonstrated that even very young children can use progressive morphology productively with nonce verbs. Moreover, it also seems to be the case that even children who show verb-island effects in word-order comprehension tests with nonce verbs (e.g. dack) are able to slot such verbs into structures organized around case-marked pronouns to produce utterances such as "He's dacking him" (Akhtar and Tomasello 1997).

Both of these findings suggest that children's early grammatical knowledge is not entirely verb-specific and, as Akhtar and Tomasello point out, imply that different aspects of the verb category are acquired by the child at different points in development. However, it is important to realize that they also undermine one of the basic tenets of the verb-island hypothesis (i.e. the claim that verbs are central to the organization of the child's grammar) and thus suggest the need to provide some kind of alternative account of why some markers come to function as "islands" in the child's grammar and others do not.

We would argue that what is required at this point is some kind of information-processing account that can explain such effects as a function of the interaction between the statistical properties of the input and the 
shape of the child's language-learning mechanism. As Braine (1987, 1988b) has argued, one way of developing such an account is to identify the limits of human distributional learning abilities and to use this knowledge as a constraint on the mechanisms proposed for natural language acquisition. According to Braine, experimental studies of artificial language learning have shown that, under serial presentation conditions, subjects readily learn the positions of words or phrases with respect to a marker. However, they have great difficulty in learning arbitrary dependencies between classes of words. One possibility, which is consistent with the results of the present study, is therefore that children's early grammatical knowledge is a complex set of relations between high-frequency markers and lexically and morphologically defined slots, which reflects the interaction between a distributional learning mechanism constrained in the way that Braine (1987) suggests and the frequency with which particular markers cooccur with particular groups or subgroups of lexical items in the input. This would imply that verb-island effects are just a special case of more general lexical learning effects that reflect the fact that, all other things being equal, individual verbs tend to occur more often and in more consistent positions in English input than do nouns and hence tend to make better high-frequency markers.

This kind of account has two advantages over a strong version of the verb-island hypothesis. The first is that it provides a mechanistic explanation of verb-island effects that avoids the need to appeal to a relation between the noun-verb distinction at the syntactic level and some kind of argument-predicate distinction at the semantic level. The second is that it can account not only for verb-island effects, but also for the presence of lexically specific knowledge organized around other highfrequency markers and can thus explain why some children show verbisland effects in word-order comprehension tests with nonce verbs but are nevertheless able to slot nonce verbs into structures based around case-marked pronouns (Akhtar and Tomasello 1997).

Of course, in order to test such an account it will be necessary to develop more detailed predictions about the shape of children's early grammars, and then to test these predictions against additional data on children's early multiword speech. Moreover, it ought to be clear from the previous discussion that, given the likely complexity of the child's knowledge at any particular point in development, this is actually a farfrom-straightforward task. Indeed, it seems to us that the only viable way of developing such predictions is to build some kind of computational model of the distributional learning mechanism involved and to use this as a kind of hypothesis-generating machine (see Gobet and Pine 1997 for a preliminary attempt to build such a model). We would therefore 
argue that, in addition to providing evidence against both a syntactic performance-limitation account and a strong version of the verb-island hypothesis, the results of the present study have two further implications for future research. The first is the need to implement constructivist accounts of early language development as computational models so that they can be used not only to test researchers' intuitions about the likely effect of the interaction between a particular learning mechanism and a particular pattern of input, but also to generate hypotheses for future research. The second is the need to produce more detailed descriptions of children's early multiword speech based on corpora much larger than those typically used in current language-acquisition research so that these descriptions can be used as targets for simulation.

Received 30 June 1997

Revised version received

6 October 1997
University of Nottingham University of Manchester University of Nottingham

\section{Note}

1. We would like to thank all the families that took part in the research reported here. This research was funded by the Economic and Social Research Council, grant numbers R000234221 and R000236393. Correspondence address: Julian M. Pine, Department of Psychology, University of Nottingham, NG7 2RD, UK. Telephone +44 1159515285. Fax +44115951 5324. E-mail jp@psyc.nott.ac.uk.

\section{References}

Akhtar, Nameera; and Tomasello, Michael (1997). Young children's productivity with word order and verb morphology. Developmental Psychology 33, 952-965.

Bloom, Lois; Lifter, Karin; and Hafitz, Jeremie (1980). Semantics of verbs and the development of verb inflection in child language. Language 56, 386 412.

Bowerman, Melissa (1985). What shapes children's grammars? In The Cross-Linguistic Study of Language Acquisition, vol. 2: Theoretical Issues, D. I. Slobin (ed.). Hillsdale, NJ: Erlbaum.

Braine, Martin D. S. (1976). Children's first word combinations. Monographs of the Society for Research in Child Development 41(1), Serial No. 164.

- (1987). What is learned in acquiring word classes - a step towards an acquisition theory. In Mechanisms of Language Acquisition, B. MacWhinney (ed.). Hillsdale, NJ: Erlbaum.

-(1988a). Review of Language Learnability and Language Development by S. Pinker. Journal of Child Language 15, 189-199.

-(1988b). Modeling the acquisition of linguistic structure. In Categories and Processes in Language Acquisition, Y. Levy, I. M. Schlesinger, and M. D. S. Braine (eds.). Hillsdale, NJ: Erlbaum. 
- (1992). How much innate structure is needed to bootstrap into syntax. Cognition 45, $77-100$.

Brown, Roger (1973). A First Language: The Early Stages. Cambridge, MA: Harvard University Press.

Clark, Eve V. (1996). Early verbs, event-types, and inflections. In Children's Language, vol. 9, C. E. Johnson and J. H. V. Gilbert (eds.). Mahwah, NJ: Erlbaum.

Elman, Jeffrey L. (1990). Finding structure in time. Cognitive Science 14, 179-211.

Gathercole, Virginia (1985). "He has too much hard questions": the acquisition of the linguistic mass-count distinction in much and many. Journal of Child Language 12, 395-415.

Gobet, Fernand; and Pine, Julian (1997). Modelling the acquisition of syntactic categories. In Proceedings of the Nineteenth Annual Meeting of the Cognitive Science Society. Hillsdale, NJ: Erlbaum.

Gordon, Peter (1985). Evaluating the semantic categories hypothesis: the case of the count/mass distinction. Cognition 20, 209-242.

Guilfoyle, Eithne; and Noonan, Marie (1992). Functional categories and language acquisition. Canadian Journal of Linguistics 37, 241-272.

Karmiloff-Smith, Annette (1979). A Functional Approach to Child Language: A Study of Determiners and Reference. Cambridge: Cambridge University Press.

Kuczaj, Stan A.; and Maratsos, Michael P. (1983). Initial verbs of yes-no questions: a different kind of grammatical category. Development Psychology 19, 440-444.

Levy, Yonata (1983a). The acquisition of Hebrew plurals: the case of the missing gender category. Journal of Child Language 10, 107-121.

- (1983b). It's frogs all the way down. Cognition 15, 75-93.

- (1988). The nature of early language: evidence from the development of Hebrew morphology. In Categories and Processes in Language Acquisition, Y. Levy, I. M. Schlesinger, and M. D. S. Braine (eds.). Hillsdale, NJ: Erlbaum.

Lieven, Elena V. M.; Pine, Julian M.; and Baldwin, Gillian (1997). Lexically-based learning and early grammatical development. Journal of Child Language 24, 187-219.

MacWhinney, Brian (1995). The CHILDES Project: Tools for Analysing Talk, 2nd ed. Hillsdale, NJ: Erlbaum.

-; and Snow, Catherine (1985). The Child Language Data Exchange System. Journal of Child Language 12, 271-296.

--; and Snow, Catherine (1990). The Child Language Data Exchange System: an update. Journal of Child Language 17, 457-472.

Maratsos, Michael P. (1982). The child's construction of grammatical categories. In Language Acquisition: The State of the Art, E. Wanner and L. Gleitman (eds.). Cambridge: Cambridge University Press.

- (1988). The acquisition of formal word classes. In Categories and Processes in Language Acquisition, Y. Levy, I. M. Schlesinger, and M. D. S. Braine (eds.). Hillsdale, NJ: Erlbaum.

- (1990). Are actions to verbs as objects are to nouns? On the different semantic bases of form, class, category. Linguistics 28, 1351-1379.

-; and Chalkley, Mary Anne (1980). The internal language of children's syntax: the ontogenesis and representation of syntactic categories. In Children's Language, vol. 2., K. E. Nelson (ed.). New York: Gardner.

Mills, Anne E. (1986). The Acquisition of Gender: A Study of English and German. Berlin: Springer.

Olguin, Rachel; and Tomasello, Michael (1993). Twenty-five-month-old children do not have a grammatical category of verb. Cognitive Development 8, 245-272. 
Perez-Pereira, Miguel (1991). The acquisition of gender: what Spanish children tell us. Journal of Child Language 18, 571-590.

Peters, Ann M. (1983). The Units of Language Acquisition. Cambridge: Cambridge University Press.

Pine, Julian M.; and Lieven, Elena V. M. (1993). Reanalysing rote-learned phrases: individual differences in the transition to multi-word speech. Journal of Child Language 20, 551-571.

-; and Lieven, Elena V. M. (1997). Slot-and-frame patterns and the development of the determiner category. Applied Psycholinguistics 18, 123-138.

-; Lieven, Elena V. M.; and Rowland, Caroline F. (1996). Observational and checklist measures of vocabulary composition: what do they mean? Journal of Child Language 23, 573-589.

-; Lieven, Elena V. M.; and Rowland, Caroline F. (1997). Stylistic variation at the "singleword" stage: relations between maternal speech characteristics and children's vocabulary composition and usage. Child Development 64, 807-819.

-; and Martindale, Helen (1996). Syntactic categories in the speech of young children: the case of the determiner. Journal of Child Language 23, 369-395.

Pinker, Steven (1984). Language Learnability and Language Development. Cambridge, MA: Harvard University Press.

Pye, Clifton (1990). The acquisition of ergative languages. Linguistics 28, 1291-1330.

Rispoli, Matthew (1994). Pronoun case overextension and paradigm building. Journal of Child Language 21, 157-172.

Rubino, Rejane B.; and Pine, Julian M. (1998). Subject-verb agreement in Brazilian Portuguese: what low error rates hide. Journal of Child Language 25, 35-59.

Tomasello, Michael (1992). First Verbs: A Case Study of Early Grammatical Development. Cambridge: Cambridge University Press.

-; and Brooks, Patricia J. (i.p.). Early syntactic development: a construction grammar approach. In The Development of Language, M. Barrett (ed.). London: UCL Press.

-; and Olguin, Rachel (1993). Twenty-three-month-old children have a grammatical category of noun. Cognitive Development 8, 451-464.

Valian, Virginia (1986). Syntactic categories in the speech of young children. Development Psychology 22, 562-579.

- (1991). Syntactic subjects in the early speech of American and Italian children. Cognition $40,21-81$. 